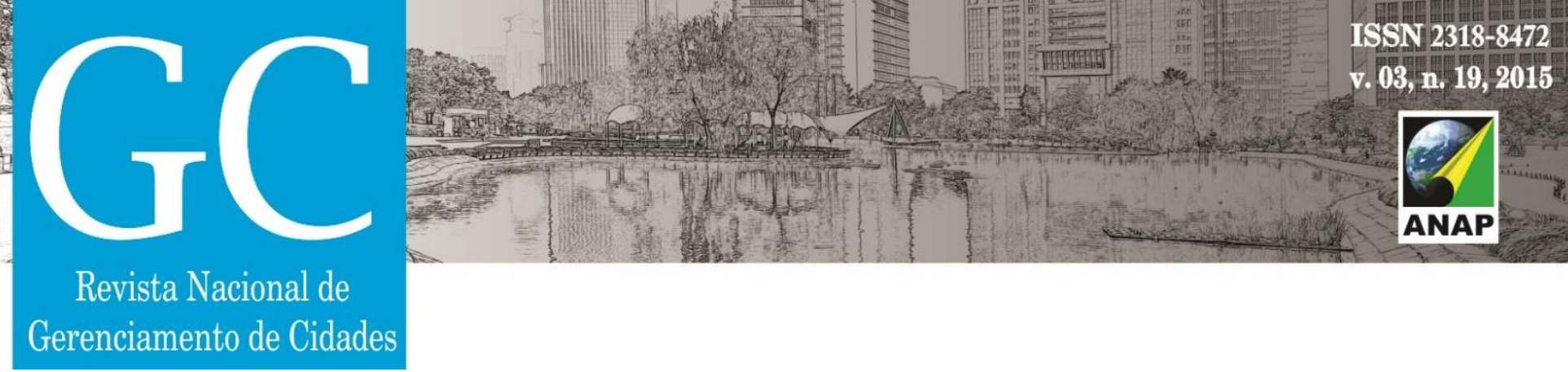

\title{
O DESPEJO DE RESÍDUOS SÓLIDOS NAS OCUPAÇÕES IRREGULARES NO CANAL DO JANDIÁ (MACAPÁ-AP).
}

\author{
Marcelle Alves Cardoso ${ }^{1}$ \\ Pablo Diego M. Mota ${ }^{2}$ \\ Luciana Carvalho da Silva ${ }^{3}$ \\ Sibelle Cavalcante Monteiro ${ }^{4}$ \\ José F. C. Ferreira ${ }^{5}$
}

\begin{abstract}
RESUMO
O município de Macapá vivencia uma relação de estreita proximidade com o Rio Amazonas em virtude do seu recorte territorial. Os canais, igarapés, lagoas e ressacas que cortam o município exercem a função de drenagem natural das águas superficiais até o Rio Amazonas. Em sua maioria, as margens são ocupadas irregularmente e os Resíduos Sólidos são despejados diretamente no local, como sucede no Canal do Jandiá, foco do presente estudo. Metodologicamente faz se uso da pesquisa bibliográfica e documental, e observação in loco. $\mathrm{O}$ objetivo consiste em evidenciar as causas do despejo incorreto dos resíduos sólidos e expor alternativas que amenizem os impactos ambientais gerados por tais ações, além de propor soluções que as interrompam e minimizem as consequências.
\end{abstract}

Palavras-Chave: Resíduos sólidos urbanos; Ocupação urbana irregular; Canal do Jandiá; Macapá.

\footnotetext{
1 Graduanda do Curso de Arquitetura e Urbanismo. Universidade Federal do Amapá. E-mail: celle_mac16@hotmail.com

${ }_{2}^{2}$ Graduando do Curso de Arquitetura e Urbanismo. Universidade Federal do Amapá. E-mail: pablodiego.mota@gmail.com

3 Graduanda do Curso de Arquitetura e Urbanismo. Universidade Federal do Amapá. E-mail: luciana0508@gmail.com

${ }_{4}$ Graduanda do Curso de Arquitetura e Urbanismo. Universidade Federal do Amapá. E-mail: sibelle.monteiro@hotmail.com

5 Professor da disciplina de "Saneamento Urbano". Pós-doutorando do Programa de PósGraduação/Mestrado em Desenvolvimento Regional da UNIFAP. Colaborador do CICS.NOVA da Universidade Nova de Lisboa. Bolsista PNDP/CAPES. E-mail: zfcofer@gmail.com.
} 


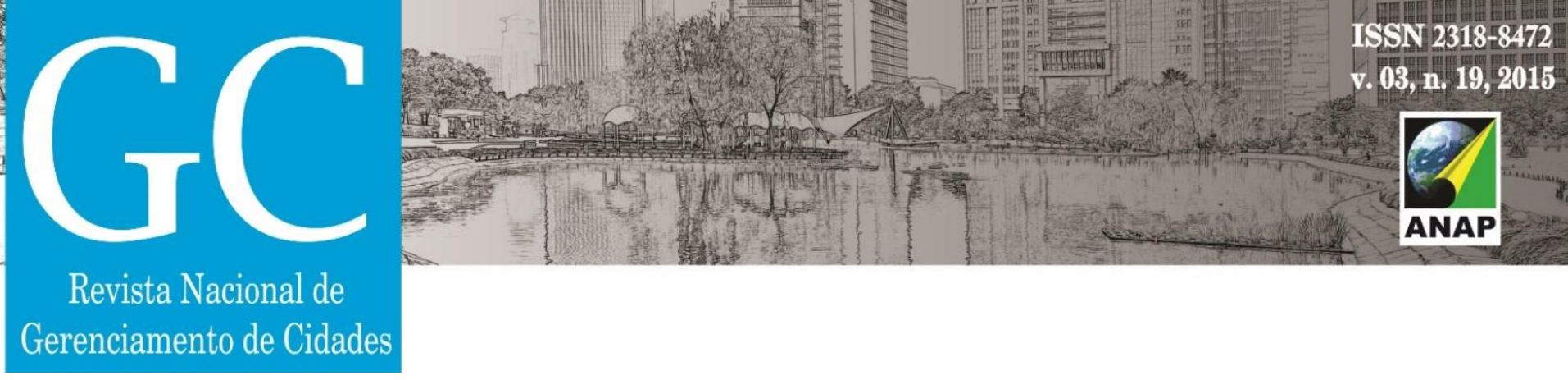

infectocontagiosas pela uso da água contaminada do canal. (MORAES, 2007; AMORIM et al, 2009; CUNHA 2012).

A problemática dos resíduos sólidos urbanos é de escala global, em todos os níveis (prefeitura, estado e União). a produção dos resíduos sólidos urbanos necessita atenção especial por parte dos gestores, com o intuito de implantar ações que reduzam a sua geração e seus impactos. Neste contexto, é possível encontrar espaço para vários atores a serem beneficiados com a correta gestão dos resíduos sólidos (habitantes, catadores, comerciantes e etc.). Ainda que as políticas públicas brasileiras apresentem uma atuação tardia, os Estados procuram adequar-se às atuais normas, como é o caso da Lei no 12.305/2010, que institui a Política Nacional de Resíduos Sólidos Urbanos. Publicada somente em 2010, depois de um complexo processo que durou quase 20 anos para ser concluído, esta lei regulamentou a destinação dos resíduos sólidos urbanos, aliado aos instrumentos de gestão eficiente, como a coleta seletiva e os planos de resíduos sólidos a todos os níveis da administração (GÓES, 2011).

Em Macapá, o poder público negligenciou por muitos anos a problemática dos resíduos sólidos urbanos, ao manter o "lixão" a céu aberto como destino final da coleta de todo os resíduos do município. Somente em 2005 o poder público do municipal executa ações de adequação para o "correto" destino final dos resíduos sólidos urbanos, ao transformar o lixão em aterro controlado. Entretanto, segundo Goês (2010), sua gestão permanece negligenciada quando se trata do serviço de limpeza urbana, coleta de lixo, tratamento e destinação final ambientalmente adequada, sem o seu gerenciamento integrado e sustentável.

O presente artigo busca evidenciar as causas para o despejo de resíduos sólidos pela população residente no entorno do canal, tendo em vista que as ações de combate e controle, por parte do poder público, são ineficazes e acabam agravando o quadro de poluição do canal do Jandiá. O objetivo central é discutir a participação da população no que diz respeito aos hábitos e ações, quanto aos resíduos sólidos urbanos, e identificar os impactos gerados pela negligência e 


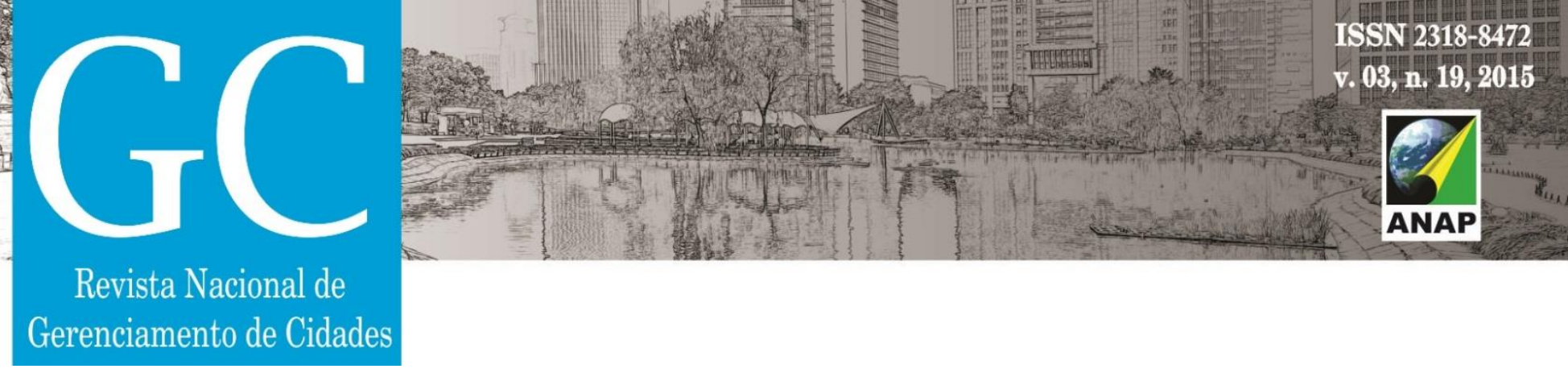

contínuo despejo de resíduos no Canal. Como metodologia, contou-se com a pesquisa bibliográfica e documental, além da observação in loco.

No primeiro item serão abordadas as características e a atual situação do Canal do Jandiá, juntamente com os hábitos da população residente no entorno. No segundo item se apresentam os impactos gerados pelo despejo dos resíduos no canal e se reflete sobre participação dos atores envolvidos, como o poder público e a comunidade.

\section{CANAL DO JANDIÁ E HÁBITOS POPULACIONAIS}

O canal do jandiá tem uma extensão de cerca de $4,2 \mathrm{~km}$, drena parte dos bairros Santa Rita e Laguinho e passa pelos bairros Cidade Nova, Pacoval, Jesus de Nazaré e São Lázaro. Constitui-se um dos pontos de atracação de embarcação na orla de Macapá. As embarcações que navegam pelo canal são de pequeno porte e servem para distribuir e escoar as madeiras para madereiras do entorno.

Figura 1 - Localização do Canal do Jandiá (Macapá-AP)

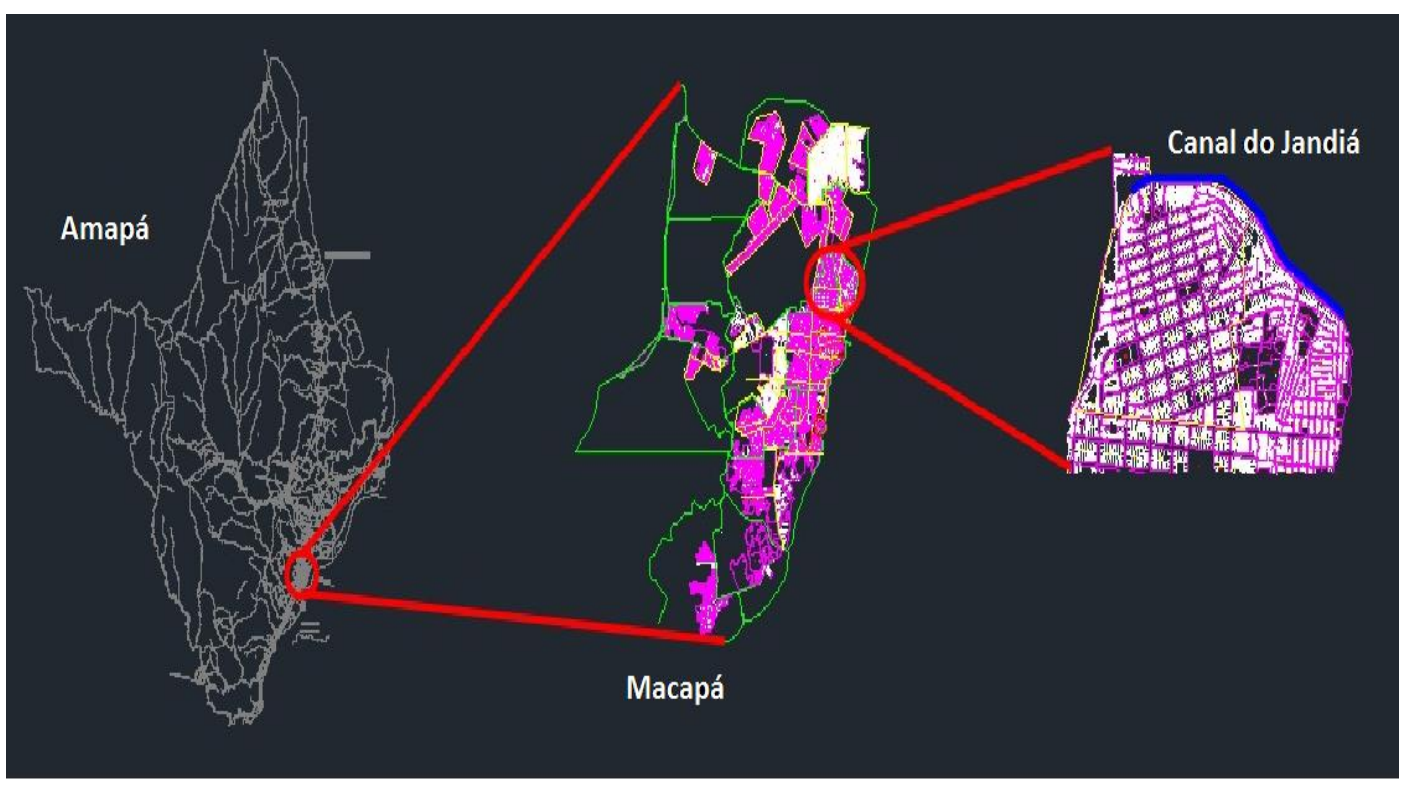

Acervo dos autores, 2015 
Revista Nacional de

Gerenciamento de Cidades

Devido ao assoreamento e à presença de plantas aquáticas o trecho de navegação nessa área diminuiu. Existem margens irregularmente ocupadas por casas, sem infraestrutura de drenagem e saneamento básico, acumulando resíduos, com tubulações clandestinas de esgoto. Em outras margens do canal, apenas se observa a vegetação nativa.

Figura 2 - Fotos da área de estudo

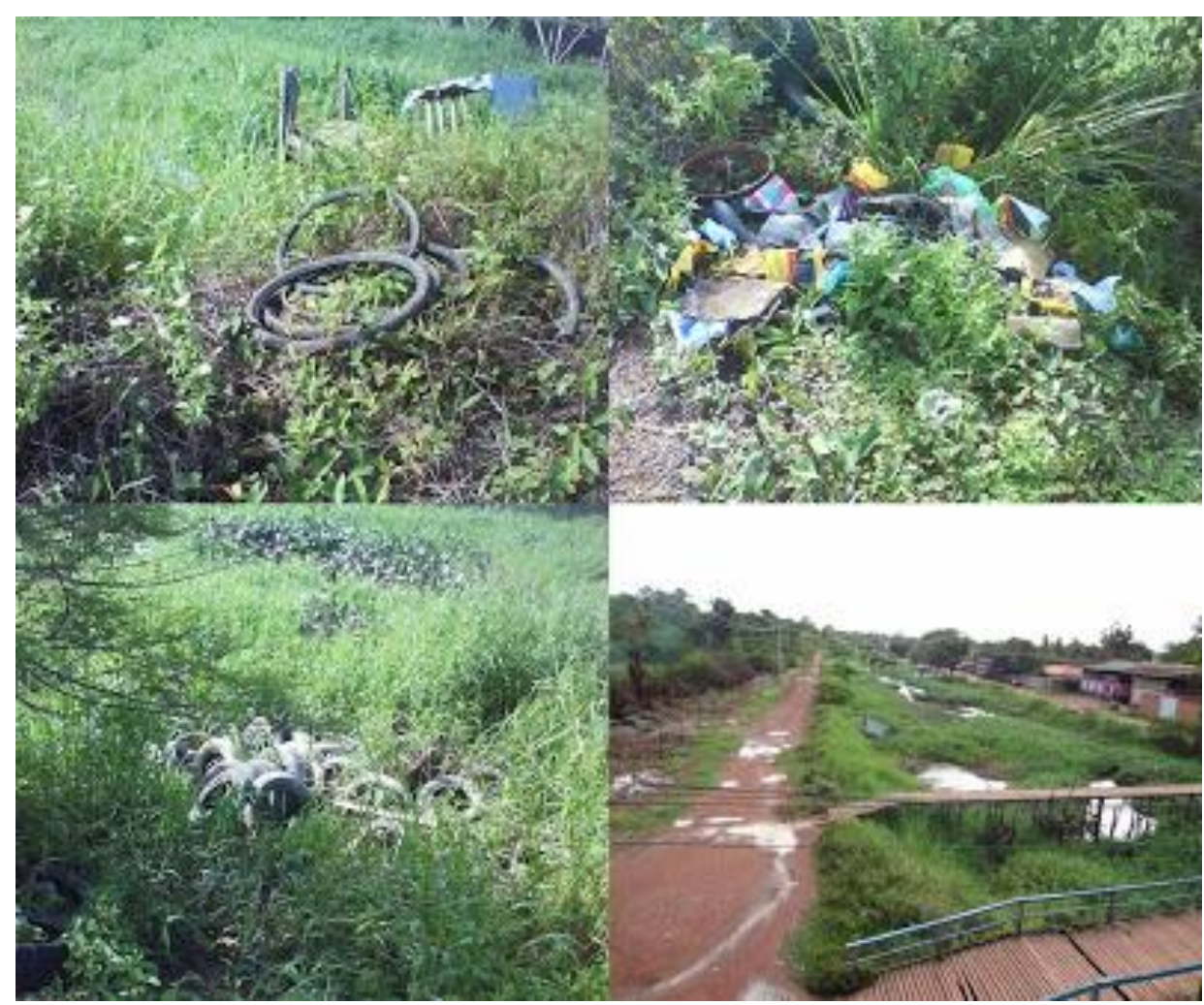

Fonte: Foto de Rogério Castelo tirada às margens da Ponte Sérgio Arruda no bairro Pacoval.

Disponível em<http://g1.globo.com/ap/amapa/noticia/2014/08/lixeiras-viciadas-poluem-margens-decanal-de-acesso-ao-rio-amazonas.html>. Acesso em 15/05/2015.

Quanto aos resíduos, existe um descompromisso visível por parte da população, constatável in loco. Não existe uma ação conjunta da população com a 


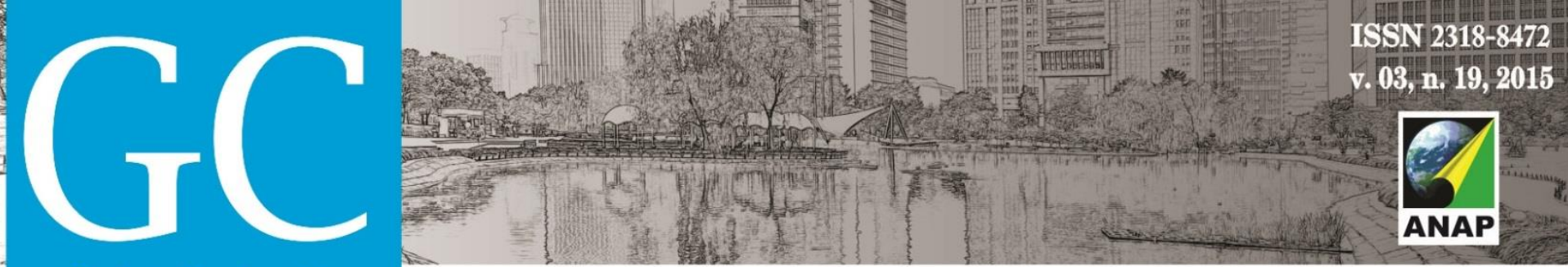

Revista Nacional de

Gerenciamento de Cidades

administração pública, promovendo o saneamento básico, juntamente com a atitude consciente de cada cidadão em práticas de educação ambiental.

Nos bairros adjacentes ao canal podemos encontrar diversas estruturas sociais, como escolas, postos de saúde e mercearias (observação no local). Somente no bairro do São Lázaro existem 4 escolas, sendo 3 estaduais e 1 municipal. além disso, evidencia-se um grande crescimento no setor comercial.

Logo após a ponte Sérgio Arruda, há cerca de 10 bairros onde mora $1 / 4$ da população da cidade (aproximadamente 100 mil habitantes). O setor comercial, antes concentrado no centro de Macapá, tem se expandido nesta região, onde podemos encontrar também vários empreendimentos e alguns importantes prédios da administração pública, entre outros a justiça federal e a polícia federal.

Quanto às estruturas escolares, o maior problema é a ausência de escola para ensino infantil, obrigando as crianças a irem atrás de escolas em bairros mais distantes, tornando uma disputa efetiva por vagas na rede de ensino macapaense.

Nas áreas baixas e de difícil acesso - áreas de ressaca - percebe-se um intenso e consolidado espaço habitacional, ligadas através de pontes de madeira. Estes se constituem locais de importância ecológica, que não podem ser ocupados. Essa ocupação ilegal se torna um ambiente não propicio à moradia, com falta de saneamento básico, infraestrutura e sujeito a doenças locais. Com essas carências, o risco de incêndios, alagamentos periódicos e crimes diversos se tornam intenso (TOSTES, 2011).

A ocupação destas áreas decorre da falta de uma política habitacional satisfatória frente ao número de migrantes e inchaço populacional (SOUZA, 2014). $\mathrm{Na}$ verdade, está-se no meio de um importante dilema: o do direito à moradia, defendido pela Constituição Federal de 1988, artigo 5ํ e 6으, e o de proteção destas áreas, que são fundamentais para a amenização do clima da cidade e para o escoamento natural das águas superficiais. A manutenção da função natural destas áreas é crucial para o ótimo funcionamento dos ecossistemas e para evitar a exposição a riscos, sobretudo o de inundação (MILLER e SPOOLMAN, 2012). 


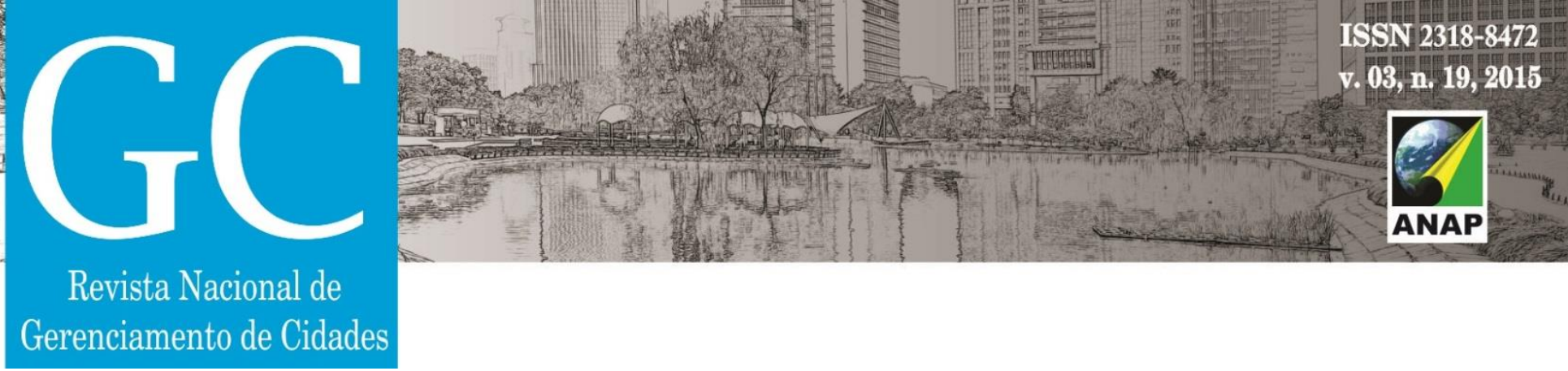

\section{IMPACTOS GERADOS COM O DESPEJO DOS RESÍDUOS SÓLIDOS NO CANAL DO JANDIÁ}

O despejo de resíduos sólidos nos canais é um problema que afeta diversas cidades de todo o país, com particular destaque para a realidade nas cidades da região amazônica, que são recortadas por igarapés, rios, canais, ressacas e lagoas, sendo estes de fundamental importância para o escoamento das águas superficiais e que se encontram poluídos e prejudicados na sua funcionalidade natural.

Em se tratando do município de Macapá, dando ênfase ao canal do jandiá, percebemos que essa prática se reproduz, o que gera diversos problemas que afetam a qualidade de vida da população, não apenas da que vive no seu entorno, mas por todo o município, em seus impactos ambientais e sociais.

O canal do Jandiá é um dos principais mananciais que cortam o município de Macapá, passando pelos bairros Cidade Nova, Perpétuo Socorro, Pacoval e São Lázaro. No seu trajeto existem vias de grande circulação, que ligam a zona norte ao restante da cidade. Sendo assim, sua localização abrange e interliga diversas áreas e bairros, sendo estratégico e de fácil acesso.

A ocupação irregular do seu entorno, sobretudo das áreas de ressaca, com saneamento básico inexistente, deficiente coleta de entulhos e de lixo doméstico, associados aos maus hábitos da população e a práticas de despejo de resíduos sólidos na área do canal, acaba por o caracterizar como "lixão a céu aberto". Entretanto, se nada for feito a respeito, a situação tenderá a agudizar-se e a comprometer, definitivamente, as funções naturais do canal. 


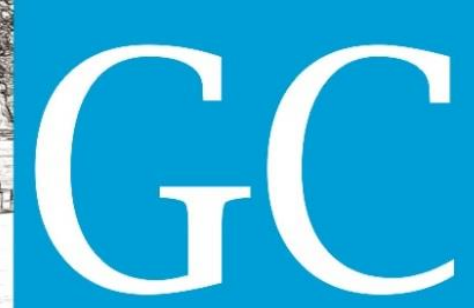

Revista Nacional de Gerenciamento de Cidades

Figura 3 - Identificação dos bairros que abrangem o Canal do Jandiá.

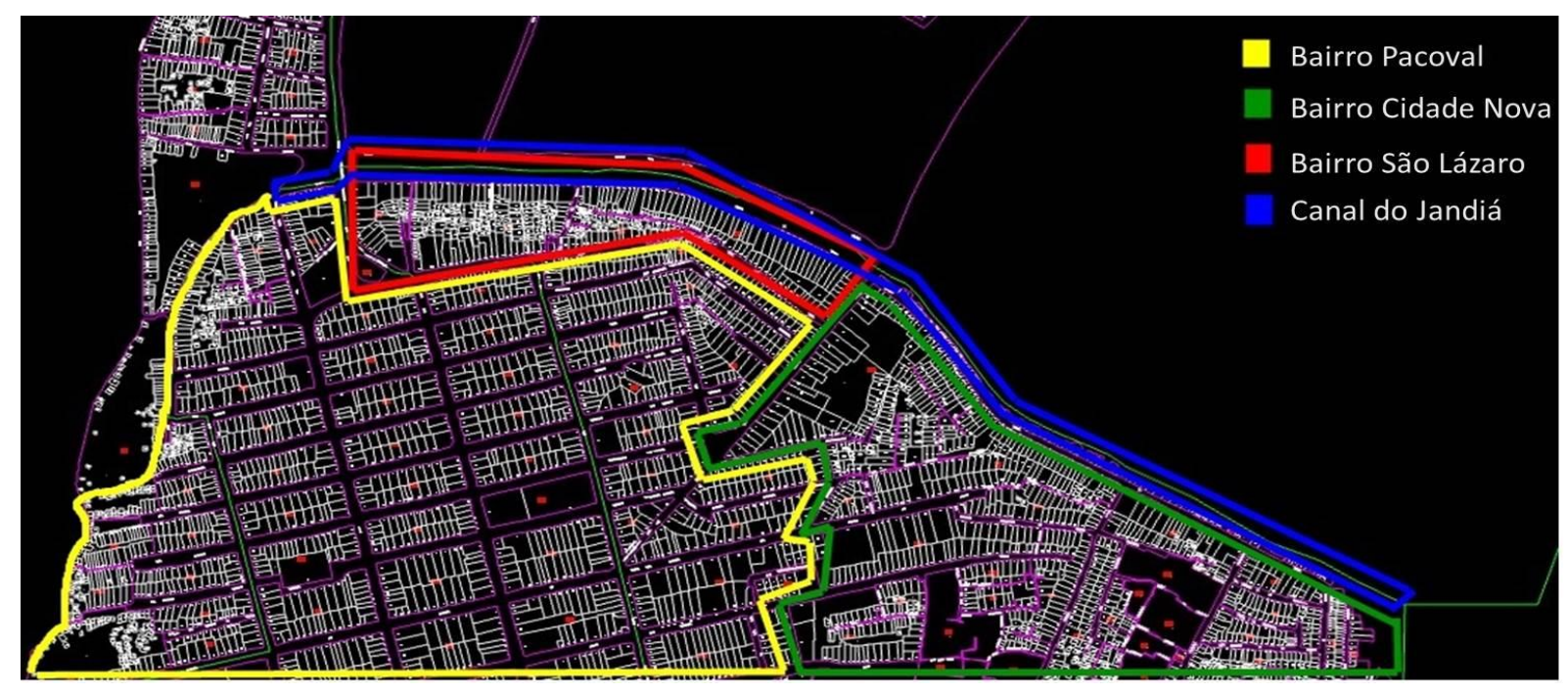

Acervo dos autores, 2015

Podemos afirmar que o crescimento populacional acentuado e a ausência de planejamento se reflete, entre outros aspectos, diretamente na produção de lixo urbano e no seu destino. O despejo de resíduos sólidos nos canais tem se tornado uma prática comum, por se tratarem de áreas ocupadas, de forma irregular, desordenada e ilegal, sem infraestrutura adequada e péssimas condições de moradia (TOSTES, 2011).

Geralmente, o lixo gerado nessas áreas é depositado diretamente no canal e nas suas proximidades. Podemos, assim, assistir a um processo de "bola de neve", em que quatro fatores interagem acentuando o problema. Por um lado, o crescimento acentuado da população que, procurando onde morar, invade estas áreas. Por outro lado, a relação deste crescimento com maior produção de resíduos (mais pessoas, mais resíduos). Em terceiro lugar, a quase ausência do poder público que, pensando a curto-prazo (próximo mandato), vai assistindo as populações destes espaços, sem resolver, definitivamente, a questão, o que se reflete na quase total ausência de políticas públicas de habitação ajustadas às especificidades locais. Por último, a população que, pelas mais variadas razões, se 


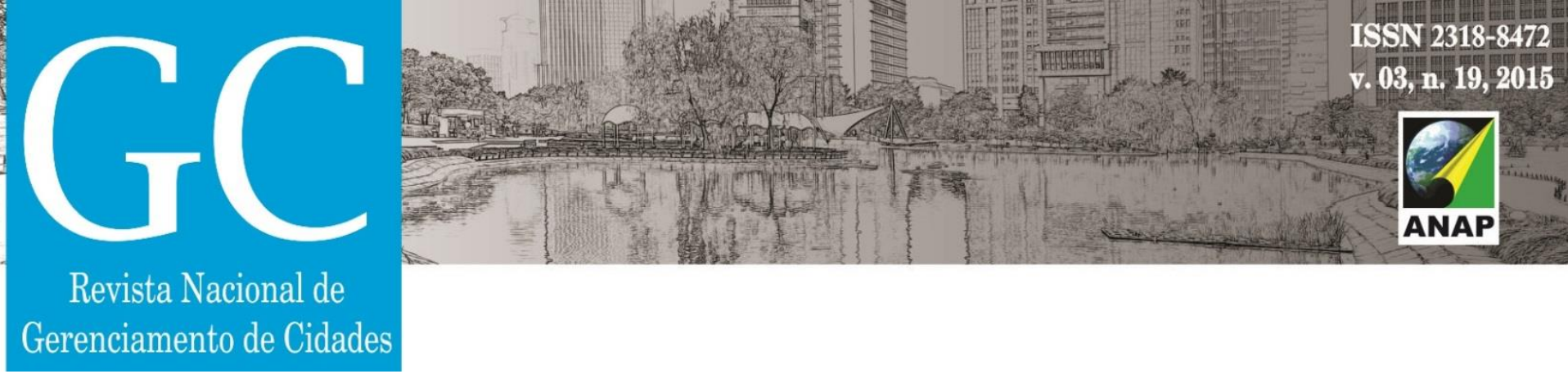

em relação à quantidade de depósitos irregulares de resíduos sólidos urbanos, recomenda-se um programa eficaz imediato de fiscalização rigorosa e ordenamento do poder público municipal.

Sem dúvida, a elaboração do Plano Municipal de Resíduos Sólidos, de preferência consorciado com outros municípios, como recomenta a Política Nacional de Resíduos Sólidos, é de crucial importância para a resolução do problema, tanto nas áreas do canais como na cidade, em geral. Pelas razões assinalas, ao longo deste trabalho, as políticas de habitação do estado e, em consequência, do município, devem estar interligadas com outras políticas, como é o caso das referentes aos resíduos sólidos urbanos.

Por último, percebe-se que a questão dos resíduos sólidos não é de responsabilidade exclusiva do poder público. Ela exige uma interrelação entre as entidades públicas, as empresas e a sociedade civil, desenvolvendo estratégias e esforços conjuntos na resolução de um problema que é de todos e que, em virtude do consumismo desenfreado que caracteriza nossas sociedades atuais, tenderá a acentuar-se. Para problema global, exige-se solução global.

\section{REFERÊNCIAS}

AMORIM, L. et al. Saúde e meio ambiente nas cidades: os desafios da saúde ambiental. Rev. Tempus. Actas em Saúde Coletiva. Brasília, 2009.

CASTILHO JR, A. B. et al. Resíduos Sólidos Urbanos: Aterro Sustentável para Municípios de Pequeno Porte. Rio de Janeiro: PROSAB - Programa de Saneamento Básico, 2003.

CHOAY, F. O urbanismo: utopias e realidade. São Paulo: Perspectiva, Col. Estudos, Série Urbanismo, n. 67, 1998.

CUNHA, Edison L. Avaliação da contaminação bacteriana e por metais pesados na orla fluvial do município de Macapá, Amapá. Macapá, Programa De Pós-Graduação Em Biodiversidade Tropical Unifap/Ci-Brasil/Embrapa-Ap/lepa/Ppgbio.,2012.

GÓES, Helívia C. Coleta seletiva, planejamento municipal e gestão de resíduos sólidos em Macapá/AP. Planeta Amazônia: Revista Internacional de Direito Ambiental e Políticas Públicas Macapá, n. 3, p. 45-60, 2011. 
